\title{
Peer-assisted Learning (PAL) as an Instructional Tool in Undergraduate Dental Education
}

\author{
Ambreen Afzal Ehsan \\ Department of Orthodontics, Altamash Institute of Dental Medicine, Karachi, Pakistan
}

\begin{abstract}
Objective: To evaluate the difference in peer-assisted learning (PAL) and expert-assisted learning (EAL) sessions for selected topics of orthodontics, conducted by either a peer or faculty member, respectively as measured by their test scores.

Study Design: Experimental study.

Place and Duration of Study: Department of Orthodontics, Altamash Institute of Dental Medicine (AIDM) Karachi, Pakistan, from October 2019 to March 2020.

Methodology: The study was carried out with the final year undergraduate dental students in the subject of orthodontics, selected by using non-probability sampling method. Selected students were given an introductory lecture on PAL approach at the start of the study. Two PAL sessions were conducted in smaller groups with all students utilised as an adjunct to traditional large group lectures; and at the end assessment was conducted comprising of multiple choice questions (MCQ). For the consecutive four weeks, same students went through traditional EAL, followed by similar type of assessment. Their test scores were compared for significance, set at $p<0.05$.

Results: A total of six sessions were conducted, two faculty members (professors of orthodontics) conducted two sessions each, and subsequent two sessions were conducted by employing PAL approach by students (earlier trained by the faculty). The mean differences in the scores of students was compared between faculty teaching and PAL-related teaching. It was observed that the EAL group significantly performed better than PAL group $(p<0.05)$.

Conclusion: In terms of test scores, academic performance and overall learning in PAL sessions was not higher than EAL group. Nonetheless, PAL can be utilised as an important supplement to synchronous teaching tele-presence by faculty as being practised during current pandemic situation in many medical and dental institutes.
\end{abstract}

Key Words: Peer-assisted learning, Educational strategies, Professional development, Expert-assisted learning, Ethical review committee, Team-based learning.

How to cite this article: Ehsan AA. Peer-assisted Learning (PAL) as an Instructional Tool in Undergraduate Dental Education. J Coll Physicians Surg Pak 2020; 30(11):1184-1187.

\section{INTRODUCTION}

Peer-assisted learning (PAL) can be defined as "people from similar social groupings that are not professional teachers yet helping each other to learn themselves by teaching". ${ }^{1}$ Teaching and learning are the two sides of the same coin. ${ }^{2}$ The most accepted principle for measuring good teaching is the amount of student learning. ${ }^{3}$ PAL is one of many educational strategies that can assiststudents' learning and their professional development. PAL refers to students learning with and from each other as fellow learners without any implied authority to any individual.

Correspondence to: Dr. Ambreen Afzal Ehsan, Department of Orthodontics, Altamash Institute of Dental Medicine, Karachi, Pakistan

E-mail:drafzalehsan@gmail.com

Received: June 16, 2020; Revised: September 29, 2020;

Accepted: October 12, 2020

DOI: https://doi.org/10.29271/jcpsp.2020.11.1184
Prior studies have identified many benefits of PAL as a teaching strategy for adults. ${ }^{4}$ These benefits include enhanced overall learning, improved long term memory and accentuated team spirit.

Effectiveness of various teaching methods has been evaluated earlier; and the concept of PAL got better overall rating. ${ }^{2}$ The impact of PAL-associated with team-based learning (TBL) of dental students was found to increase the overall learning. ${ }^{5}$ Coaching of medical students appears to profit both learners as well as peers. ${ }^{6}$ Involving students in education not only promotes their interest in an academic pathway, but also furnishes them with a range of skills which can be used by them as future educators in their career. During education, the journey between novice and master with both learning and teaching tasks is a valuable source of education. ${ }^{7}$

Dental educators today struggle to provide remedial and supplementary instructions to address the wide range of student abilities and needs within the classroom. PAL encourages the students to become more active and independent learners, assuming greater responsibility for their own learning as well as that of their peers. 
Table I: Comparison of pre- \& post-test scores of faculty and students for each session.

\begin{tabular}{|l|c|c|c|c|}
\hline Faculty / student & $\mathbf{n}$ & Pre-score & Post-score \\
\hline Faculty 1 session 1 & 55 & $32.95 \pm 14.67$ & $46.84 \pm 21.14$ \\
\hline Faculty 1 session 2 & 57 & $48.25 \pm 21.89$ & $53.28 \pm 21.14$ & $<0.001$ \\
\hline Faculty 2 session 1 & 57 & $47.46 \pm 17.81$ & $52.46 \pm 21.43$ \\
\hline Faculty 2 session 2 & 58 & $47.59 \pm 15.90$ & $53.97 \pm 21.25$ & 0.041 \\
\hline PAL session 1 & 58 & $58.97 \pm 19.07$ & $62.50 \pm 15.08$ & 0.007 \\
\hline PAL session 2 & 57 & $60.78 \pm 16.96$ & 0.107 \\
\hline
\end{tabular}

Table II: Overall comparison of pre- \& post-test scores among faculty and students.

\begin{tabular}{|l|c|c|c|c|}
\hline Faculty/ Pal & $\mathbf{n}$ & Pre-score & Post-score & p-value \\
\hline Faculty & 227 & $44.12 \pm 18.79$ & $51.65 \pm 21.29$ & 0.001 \\
\hline Students & 115 & $59.87 \pm 17.99$ & $62.43 \pm 16.01$ & 0.255 \\
\hline
\end{tabular}

At present, PAL is not being used as a formal instructional strategy in the dental institutions, although they can benefit both professionally and academically. Therefore, it is felt that there exists a gap to explore the domain of PAL to assess its effectiveness and applicability in undergraduate dental education, and the possibility of adopting PAL as a formal teaching tool. So, the rationale of this research was to establish the differences in the learning of selected topics by the final year BDS students (both peer tutors and tutees) as part of undergraduate programme, with an objective of assessing the educational/learning remuneration for the students who participated in PAL. The results of this research might pave the way for dental educationists to use PAL at undergraduate level as a useful additional instructional strategy. The study was conducted to determine the effectiveness, utilising PAL as well as EAL sessions conducted by either a peer or faculty member respectively as measured by their test scores.

\section{METHODOLOGY}

This experimental study was conducted at the Department of Orthodontics, Altamash Institute of Dental Medicine (AIDM), Karachi, Pakistan, from October 2019 to March 2020. Sample size was 58 final year undergraduate dental students in the subject of orthodontics, selected using nonprobability convenience sampling technique. Study was initiated after taking approval from the Ethical Review Committee (ERC). Informed consents were obtained from all the eligible participants. The PAL approach selected was learning supported by peers of the same class or level. In this group, both teachers and learners engaged concurrently. Participants (learners) were guided about benefits and aims of PAL and approaches to conduct the sessions. Team work, cooperation, constructive problem solving, and workshop planning were emphasised. The PAL sessions consisted of two groups of 25 students each (further divided into five small groups). PAL learning sessions (two) were conducted by student groups, who were trained by the faculty. The module was designed on orthodontics related topics that have been given to the PAL subgroups and presentations were to be delivered interactively to the rest of the group. The allotted time for each session was nearly an hour. The students were tested for knowledge gained in the second week after attending two PAL sessions. A 25-minute written test, consisting of MCQs, was administered to assess the group's assimilated knowledge of a pre-announced subject. Total number of MCQs used were 10 and of one best type. They were targeted to measure all three levels of cognition including $\mathrm{Cl}$ (recall), C2 (understanding) C3 (problem solving). They all were vetted by three subject specialists to validate their construct, both to the instructors and students.

In the ensuing four weeks, EAL sessions in the form of traditional tutorials were scheduled for the same class in the style of standard lectures, while the same course was still ongoing. Students had to join the EAL sessions of pre-announced topics. EAL sessions were conducted by two professors of orthodontics (two sessions each). Each EAL session with complete class of 58 students was conducted by two faculty members. The session opened the topic and answered concerns of the students, explained some logical problems etc. At the end of four EAL sessions, the students undertook a 25-minute written test consisting of MCQs. The topics of PAL and EAL sessions were of similar difficulty level. MCQs used again were of one best type. They were of same specifications as used in PAL session targeted to measure all three levels of cognition including $\mathrm{C} 1$ (recall), C2 (understanding) C3 (problem solving). They all were also vetted by three subject specialists to validate their construct, both to the instructors and students. Total numbers of MCQs were 10. Both PAL and EAL assessments comprised of MCQs, prepared and checked by same faculty member, who was not aware of the applied learning methodology.

Data was analysed using SPSS version 23. Quantitative variables like pre- and post-MCQs scores were presented as mean and standard deviation. Paired t-test was applied to compare pre- and post-test scores among faculty and students. Independent t-test was applied to compare mean change (pre- and post-tests) between faculty and students. The $p$-value $\leq 0.05$ was taken as significant. 


\section{RESULTS}

Total six sessions were conducted, two faculty members (two professors of orthodontics) conducted two sessions each and two sessions were conducted by PAL (who were trained by the faculty). In the first session, conducted by the first faculty member, 55 and 57 students were present, respectively. In the second session, conducted by the second faculty member, 57 and 58 students were present, respectively. In first and second PAL sessions, 58 and 57 students were present, respectively. In the first session conducted by first faculty member, the scores were significantly increased post-learning session $(p<0.05)$. Overall score increase was observed in sessions of EAL and PAL. However, the difference was not statistically significant ( $p>0.05$, Table I).

On comparing overall pre- and post-test scores for EAL and PAL, significant increase has been observed among faculty group $(p<0.05$, Table II).

The mean change in scores of students between EAL and $\mathrm{PAL}$, was significantly better for $\mathrm{EAL}$ group than $\mathrm{PAL}$ group $(7.49 \pm 18.23$ vs. $2.30 \pm 16.68, p=0.011)$

\section{DISCUSSION}

Professional education training requirements enable self-learning and team work to formulate students for their working lives. ${ }^{8}$ Personnel with similar backgrounds, who are not necessarily be professors, support each other to learn by cooperative learning in PAL. ${ }^{9,10}$ PAL helps individuals build skills and knowledge by exchanging experiences that lead to a positive understanding, and that varies whether people are on their own. The social constructivist philosophy of education and teamwork between students, work together to achieve a shared goal, which demonstrates the concept of PAL. ${ }^{11,12}$ PAL is good for academic institutions, as it provides chances to reduce the burden of teacher load and tackles curriculum gaps. ${ }^{13}$

It also helps students to build professional and communication skills, offering less challenging support for each other than experts. ${ }^{13,14}$ Hence, in the present research, the author assesses the effectiveness of PAL among undergraduate dental education.

In a previous study, students with past good performance gained most by $P A L$, in agreement to the results of Donohoe et al. and Hommes et al, who had observed that past good performance has significantly more impact on future success of students. ${ }^{15,16}$ Similarly, being a learner or a facilitator is not correlated with scores. This result is supported by previous researches; in which medical students who served as PAL tutors did not perform better overall as compared to other students with a similar background, despite academic skills. ${ }^{17}$ In the current research, the author found significant increase in scores of students after being facilitated by PAL as well as faculty. However, on comparing overall mean change in score, the author found significantly better results of students after being taught by EAL as compared to PAL $(p<0.05)$. Cameron et al. in their research found insignificant association between the performance of PAL and EAL $(p>0.05)$. It is believed that PAL can contribute to the development of graduate achievements and is also a beneficial means of providing the subject-specific instruction. ${ }^{18}$ Saeed et al. found in their research that median scores of PAL groups was lower as compared to EAL groups, but the relationship was statistically insignificant $(p<0.05)$. Therefore, the student's performance in PAL groups was not said to be better than student's performance in EAL groups. ${ }^{19}$

In the present research, the good performance of students in EAL groups might be due to familiarity of the students with EAL sessions. Throughout traditional system, external exhortation plays a greater role throughout encouraging students, instead of self-motivation, to learn and experiment, which involves modern peer-tutoring approaches. A further reason for current findings is the nature of engaging group sessions, such as PAL and EAL sessions, in which teachers encourage their students to learn by asking questions and promoting critical thinking. It is reasonable to expect a more experienced faculty to instruct its students, and that would enhance the comprehension and success of the examinations. For EAL groups in the present research, this aspect contributes to more favourable results. This finding is further verified by various researches, which show that student perform better in traditional EAL than PAL sessions. ${ }^{20-22}$

In the present study, the average assessment scores of students throughout PAL classes were no higher than those of EAL groups. Nevertheless, PAL is known to be an important student-centred learning method and could play a useful role in undergraduate dental education as adjunct teaching classroom tutorials and lectures that will promote students active participation while maintaining professional teaching. Continuing PAL sessions will not only develop students' basic abilities, but will also prepare potential dentists to perform their function as teachers at community level. However, PAL can be utilised as an important supplement to teaching by faculty. Senior students could learn valuable academic and communication skills and additionally gain teaching experience. It is expected that efficacy of PAL sessions is likely to increase proportionally with the increase in students, who acted as tutors in PAL, knowledge and experience; hence, paving way of conducting a similar study with post graduate participants. Even the factor of selecting students (undergraduate) to act as PAL tutors with previous good standing and performance is likely to produce different results.

Moreover, there is more research needed to maximise and measure the potential benefits of PAL in this e-learning envi- 
ronment forced by COVID-19 pandemic for tutees, tutors and the institutions. PAL can also be used as an important instructional tool in educational institutes, which is getting affected due to COVID-19 pandemic, and there is absence of face-to-face training of dental professionals. It will also be an important tool in reflection, feedback, teaching patient safety and preparing for practice.

\section{CONCLUSION}

In terms of test scores, academic performance in PAL sessions was no higher than EAL group.

\section{ETHICAL APPROVAL:}

This research was carried out after the approval of Ethics Committee of the Altamash Institute of Dental Medicine Karachi, Pakistan.

\section{CONFLICT OF INTEREST:}

Author declared no conflict of interest.

\section{AUTHOR'S CONTRIBUTION:}

AAE: Contributions to the conception and design of the work, principal investigator, planning, data collection / analysis, interpretation of data and manuscript writing.

\section{REFERENCES}

1. Ronal DJH. A Practical Guide for medical teachers. Elsevier 2013.

2. Sajjad S. Effective teaching methods at higher education level. Pak J Spec Edu 2010; 11:29-43.

3. Theall M, Franklin J. Looking for bias in all the wrong places: A search for truth or a witch hunt in student ratings of instruction? New directions for Institutional Research 2001; 2001(109):45-56. doi.org/10.1002/ir.3.

4. Benè $\mathrm{KL}$, Bergus G. When learners become teachers. Fam Med 2014; 46(10):783-7.

5. Al Kawas S, Hamdy H. Peer-assisted learning associated with team-based learning in dental education. Health Professions Education 2017; 3(1):38-43 doi.org/10.1016/ j.hpe.2016.08.003.

6. Ten Cate O, Durning S. Peer teaching in medical education: Twelve reasons to move from theory to practice. Med Teach 2007; 29(6):591-9. doi: 10.1080/01421590701606799.

7. Feiman-Nemser S. Helping novices learn to teach: Lessons from an exemplary support teacher. J Teacher Education 2001; 52(1):17-30. doi.org/10.1177/00224871010520 01003

8. Commission on Dental Accreditation, American Dental Association: Accreditation standards for dental education programs, 2013. http://www.ada.org/ /media/CODA/
Files/predoc.ashx (accessed June 10, 2016).

9. Jones RL, Harris R, Miles A. Mentoring in sports coaching: A review of the literature. Physical Education and Sport Pedagogy 2009; 14(3):267-84. doi.org/10.1080/174089 80801976569.

10. Boud D, Cohen R, Sampson J. Peer learning in higher education: Learning from and with each other. Routledge 2014;

11. Vygotsky LS. Mind in society: The development of higher psychological processes: Harvard university. Press 1980.

12. Johnson DW, Johnson RT. Learning together and alone: Cooperative, competitive, and individualistic learning: Prentice-Hall, Inc; 1987.

13. Abdel Salam M, El Tantawi M, Al-Ansari A, AlAgl A, Al-Harbi $F$. Informal peer-assisted learning groups did not lead to better performance of saudi dental students. Med Princ Pract 2017; 26(4):337-42. doi: 10.1159/000477731.

14. Yu TC, Wilson NC, Singh PP, Lemanu DP, Hawken SJ, Hill AG. Medical students-as-teachers: a systematic review of peerassisted teaching during medical school. Adv Med Educ Pract 2011; 2:157-72. doi: 10.2147/AMEP.S14383.

15. Donohoe CL, Conneely JB, Zilbert N, Hennessy M, Schofield S, Reynolds JV. Docemur docemus: Peer-assisted learning improves the knowledge gain of tutors in the highest quartile of achievement but not those in the lowest quartile. J Surg Educ 2015; 72(6):1139-44. doi: 10.1016/j.jsurg.2015.07.001.

16. Hommes J, Rienties B, de Grave W, Bos G, Schuwirth L, Scherpbier A. Visualising the invisible: a network approach to reveal the informal social side of student learning. Adv Health Sci Educ Theory Pract 2012; 17(5):743-57. doi: 10.1007/s10459-012-9349-0.

17. Iwata K, Furmedge DS, Sturrock A, Gill D. Do peer-tutors perform better in examinations? An analysis of medical school final examination results. Med Educ 2014; 48(7): 698-704. doi: 10.1111/medu.12475.

18. Cameron DA, Binnie VI, Sherriff A, Bissell V. Peer-assisted learning: Teaching dental skills and enhancing graduate attributes. Br Dent J 2015; 219(6):267-72. doi: 10.1038/ sj.bdj.2015.722.

19. Ahsin S, Saad K, Afzal A. Comparison of academic performance in peer assisted and expert-assisted learning through test scores. Pak J Physiol 2018; 14(4):47-50.

20. Schmidt H, Van Der Arend A, Kokx I, Boon L. Peer versus staff tutoring in problem-based learning. Instructional science 1994; 22(4):279-85.

21. Hodgson $Y$, Bearman M, Schneider-Kolsky M. Lessons learned in implementing peer-assisted learning. Int J Innov Sci Math Edu 2012; 20(3).

22. Rees EL, Quinn PJ, Davies B, Fotheringham V. How does peer teaching compare to faculty teaching? A systematic review and meta-analysis. Med Teach 2016; 38(8):829-37. doi: 10.3109/0142159X.2015.1112888. 